\title{
How to develop technology roadmaps? The case of a Hospital Automation Company
}

\author{
Giseli Valentim Rocha ${ }^{\text {a*}}$, Carlos Henrique Pereira Mello ${ }^{\text {a** }}$ \\ aniversidade Federal de Itajubá, Itajubá, MG, Brasil \\ *giselirocha@gmail.com, ***carlos.mello@unifei.edu.br
}

\begin{abstract}
This paper presents the results of research conducted in a hospital automation company. The research examined the importance of innovation and technology management processes for small companies and how these factors can be developed more successfully. The paper proposes the use of a Technology Roadmapping (TRM) method to assist these companies in the management of their technology processes to better understand the economic and social context in which they operate and to better exploit market opportunities. The results show that Technology Roadmapping can assist these companies in management support and technological planning while exploring and sharing the connection between technological resources, organizational goals and environmental changes. This research addresses the lack of studies on conducting TRM and details the importance of the method.
\end{abstract}

Keywords

Technology-based company. Technology management. Technology Roadmapping.

\section{Introduction}

Planning and managing innovation has become a central issue for organizations who want to follow and mainly induce changes in the market. The new products, services and technologies directly affect the performance of the organizations, affecting, for example, the behavior of competitors, which are more competitive, and customers, who become increasingly demanding. Thus, it is of great importance to generate new knowledge, enabling organizations to develop new products, services and technologies (Oliveira et al., 2012).

Given this reality, a change is needed in the way companies interact with each other and with the market, including a more open sharing of information. One of the tools being used to assist the development and support of new businesses is the Technology Roadmapping (TRM). Lee \& Park (2005) argue that Technology Roadmapping is one of the most used methods to support the development of technology strategies. TRM uses graphical means to visualize the relationships between products, markets and technologies.
According to Phaal et al. (2004), technological roadmaps and the mapping process itself may provide a means to visualize the organization in terms of planning horizons so that they extend along with the identification and evaluation of possible threats and opportunities in the business environment.

However, despite the process of creation of the technology roadmaps being very well described in the brochure produced by Phaal et al. (2004), many texts relate to the very "what" to do and not the "how". Thus, the process becomes a black box for those lay readers who are interested in deploying the tool in their innovation processes, especially small firms.

For this reason, the main objective of this paper is to discuss the step-by-step development of technology roadmaps, focusing on the triad Technology, Product and Market (TPM), since such details are not well explored in the literature. Therefore, the Technology Roadmapping method was applied in a technology-based company (TBC) specialized in hospital automation. The work involved the development of a procedure linking the triad TPM that provided to the responsible 
company an opportunity to understand and, thus, be able to better plan and develop their products. Thus, with this scientific contribution, TBCs and other companies to manage the technological advances of the products or services of their business can use this tool.

The paper is structured as follows: after the introduction, in the second session Tecnology Roadmapping method is presented as a method that helps organizations develop products and technology services. Then discusses the importance of technology-based companies to the country and their need to make a good technology planning. After that, the research method presents the operating logic, the differentiation between its process and its expected results, its customization aiming at adapting the application context. Session 3 proposes the development of TRM for TBCs. The session 4 presents the action research cycles and analysis of results. Finally, section 5 presents the conclusion and some of the main limitations of the research.

\section{Technology roadmapping}

One method that emerged in the 1970s is the Technology Roadmapping (TRM), which was developed by Motorola ${ }^{\circledR}$ and was later joined by other companies such as Lucent ${ }^{\circledR}, \mathrm{HP}^{\circledR}$ and Philips ${ }^{\circledR}$ (Albright \& Kappel, 2003; Lee \& Park, 2005). TRM had expanded its scope, involving sectorial studies such as the US agricultural sector and key sectors such as pharmaceuticals (Tierney et al., 2013), among others. The adaptability of this method to situations and different objectives allows assisting both studies trends of industrial sectors and the planning of a new product or new product portfolio (Oliveira \& Rozenfeld, 2010). When considering the management of technology-based companies (TBCs), there is the importance of technology management. This is a challenging activity, especially due to its multidisciplinary and multifunctional, in that it requires the engagement of business and technology functions of the company (Phaal et al., 2004).

Oliveira \& Rozenfeld (2010) consider TRM a powerful technique for supporting technology management and planning, especially to explore and communicate the dynamic links that exist between technological resources, organizational goals and changes in the external environment.

Technology Roadmapping provides a framework to visually integrate market, product, technology and evolution. In a more objective definition, Caetano \& Amaral (2011) claim that the roadmap is a method which supports organizations to describe the path to mainstream technology products and services.
Companies can use it to gather information from a variety of sources to develop new products, make medium and long-term plans of R \& D investments and new dynamism and development processes. Within a company, this tool integrates all levels in a structure that supports the initiatives and strategic decisions tactics (Phaal et al., 2004).

Technology roadmaps typically provide a time-based representation of relationships between technologies and products. That core set of relationships is often augmented with connection to markets and on occasion to the organizations involved in delivering the technologies and products (Rinne, 2004).

Roadmaps are maps representing the evolution of the product and the technologies applied. A generic map is formed by layers and generally possesses the commercial and technological perspectives (Phaal et al., 2004). The most common structure is presented in Figure 1.

In general, the process described provides a very flexible structure. In addition, the seminars (market, product and technology) can be modified, extended or compressed, depending on the objectives of the company, the information available and the unit of analysis. This feature demonstrates that the approach of the TRM is not like a "black-box" and can be adapted to the context of each organization (Phaal et al., 2007).

Despite all the benefits observed in the literature, this also indicates that there is a lack of studies that address deep mapping technological products, especially works that address the Brazilian context, which was a limitation for this research. Thus, a theoretical and even practical limitation generated the need for an adaptation of the existing theory for the international context to be replicated in the company studied in the national context.

Thus, this research presents a specific case of interaction of a research team with TBC. It can also be stated that the technology roadmapping, using the techniques available in the literature, did not occur as expected. That is because the TRM is extremely flexible and can be used for large and small businesses

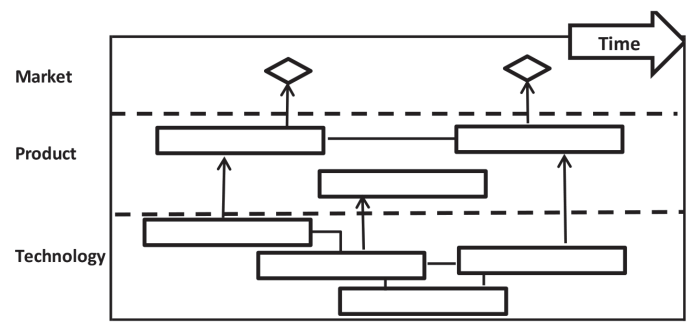

Figure 1. The general architecture of the Roadmap. Source: Phaal et al. (2004). 
in any industry. Therefore, the method could only be used with the effort for interaction and adaptation for replication of the model in the company.

\subsection{Technology-based companies}

The definition of what are technology-based companies (TBC) is far from having a clear and unique meaning in the literature. Various terms such as technology-intensive enterprises, high-tech, advanced technology, technology end, or in some cases, start-ups and emerging are used interchangeably, without a conceptual concern to distinguish them (Andrade Junior, 2014). Technology-based companies, in turn, as named by the Ministry of Science and Technology - MST (Brasil, 2013) are those whose main production device are the scientific and technological knowledge which are related intensively with universities and research institutes, making use of human resources and materials belonging to these institutions.

One of the most promising ways to promote economic and social development from the interaction between universities and the business sector is supporting the consolidation of technology-based companies primarily based on the results of academic research (Rogers et al., 2001; Shane, 2004). These projects, known as academic spin-offs, in addition to generating highly qualified jobs, create economic value for the market from the scientific and technological knowledge by developing innovative products and business (Shane 2004).

However, before they can effectively exploit this potential, it is observed that these TBCs are, in general, in a risky process of evolution (Ndonzuau et al., 2002). The difficulties encountered in these stages that precede the consolidation of the company in the market require a lot of support from various organizations aimed at promoting these spin-offs. Note that this aid cannot be limited only to policies and incentive programs, but should encompass also the development of an approach to appropriate technical and managerial support to this particular type of entrepreneurship (Gasse, 2002). Given the above, it appears that the development of TBCs in Brazil require auxiliary mechanisms support and incentives (Andrade Junior, 2014).

Practical experience shows that the phase factor for success is in the creation of the new company's initial business planning, ideally conducted in a center of technology entrepreneurship. This observation is justified, for example, by the fact that, in general, without the formalization of a new development project, not to get investments and partnerships that would be critical to launch TBC to the market. Therefore, the aid in this planning is probably one of the greatest needs of these future companies (Vohora et al., 2004).
Thus, it is important to conduct a technology planning, according to Ndonzuau et al. (2002), since it aims to further investigate the various possibilities for the industrial exploitation of the technology. Its main expected outcome is the development of the first versions (prototypes) of products, processes or value-added services. These will enable not only to check whether the production can be extended to a higher industrial scale but also to show potential customers and partners the potential technological solutions, i.e. what practical problems it can solve.

\subsection{Research method}

The research method chosen for conducting this study was action research, since, according to Thiollent (2011), it is a type of social research evidence base that is designed and carried out in close association with an action or with the resolution of a collective problem and in which researchers and participants representative of the situation or problem are involved in a cooperative or participatory form.

Action research is a generic term that covers many forms of research-oriented action and indicates diversity in theory and practice among researcher's users of this method, providing a broad range of options for potential researchers on what can be appropriate for their research questions (Coughlan \& Coghlan, 2002).

It is known that the action research contributions are more easily perceived in the practical sphere, because its results cannot be generalized. As the name suggests, action research is action and creation of knowledge. However, the contribution in theory can be constructed from the results obtained with other studies that will be stimulated from this developed case. By the use of action research method, the researchers approached the study social situation and optimized the interaction between researchers and companies and their entrepreneurs throughout the technology planning. The exchange of experiences between those involved in the social context and the generation and use of knowledge together are the benefits provided by the literature (Thiollent, 2011)

The method of action research can be understood as a visual cycle, as illustrated in Figure 2. Coughlan \& Coghlan (2002) argue that it is important to recognize the action research as one of the numerous types of research methods, which is a generic term for any process that follows a cycle in which it improves practice by systematic oscillation between acting in the field of practice and inquiring into it. It plans, implements, describes and evaluates all changes to improve their practice, learning more in the course of the research itself. 

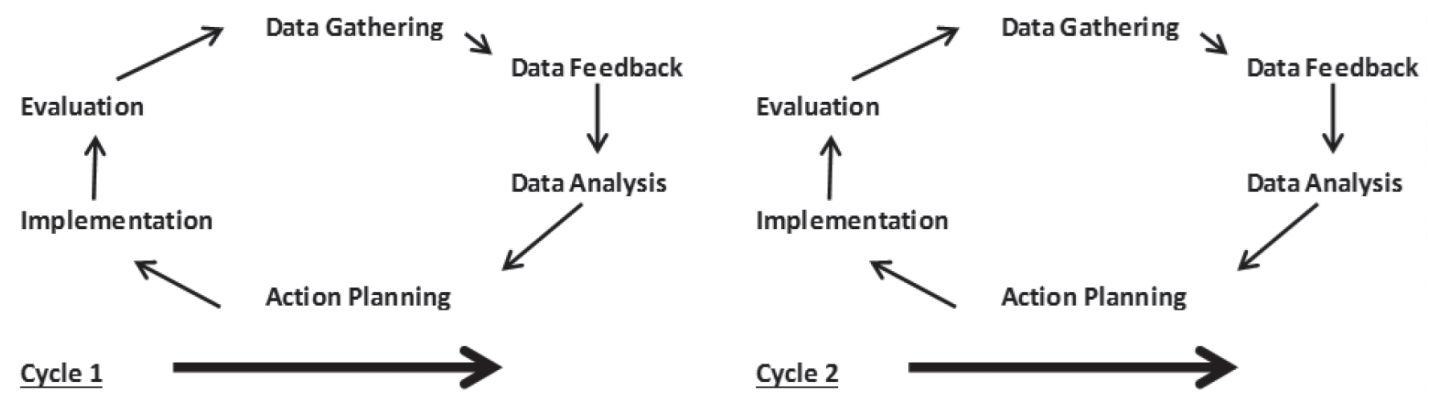

Figure 2. Steps for action research. Source: Adapted from Coughlan \& Coghlan (2002).

\subsubsection{Defining the unit of analysis}

The requirements for choosing the object of study in order to meet the objectives sought by the research were: (1) the company should be technology based; (2) it should have an organizational structure that would allow the formation of a multifunctional team to participate in research activities because technology roadmapping depends on cross-functional teams; (3) the top management should have an interest in the application of the method to develop and commit research to its end, contributing to the fullness of the work and (4) the company should accept to share the results with the researchers by confidentiality agreement.

Based on these requirements, the search for the company's definition was made in ltajubá region (Minas Gerais, Brazil), which is a city renowned for being a center of technology-based companies. Between several TBCs, a hospital automation company demonstrated the highest interest and willingness to participate, because of its need and interest in making the technology management of its businesses. For strategic reasons, the participant company requested its name to be withheld.

The company emerged in 2008 with the aim of creating innovative products for health, combining technology and innovation with the market demand. The company operates in developing, manufacturing and marketing of medical and veterinary devices, to meet the hospitals, clinics, healthcare professionals and patient's needs. The company received incentives and awards for its innovative ideas.

Among its developed products, the company selected for the study, the Automated Clinic Chair/Table, which is the main product of the company and has the greatest potential to generate income and development. It provides better conditions for health professionals to treat their patients by combining technology and the knowledge of medical professionals as shown in Figure 3.

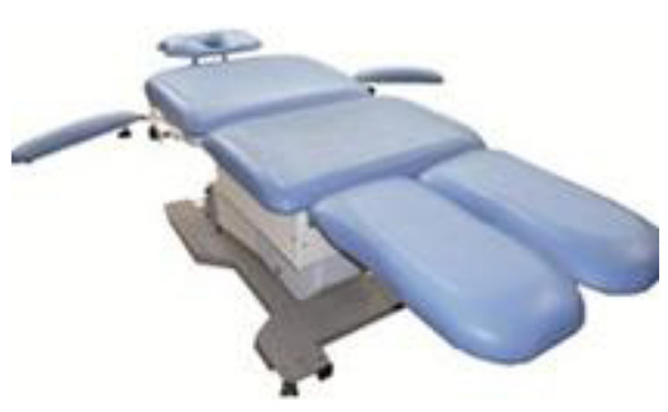

Figure 3. Automated clinic chair/table.

\section{Proposal of development of technology roadmaps in TBCs}

The strategic planning process includes activities such as assessment of the competitive environment, setting objectives and targets, positioning in the value chain, development of the business model, among others (Porter, 2008).

In general, three main activities for the development and implementation of strategies can be identified: strategic analysis (internal and external environment), strategy formulation and strategy implementation, (Johnson et al., 2008) as shown in Figure 4. Thus, this analysis model addresses the dimensions Technology, Product and Market that will be detailed in this work.

In strategic analysis, which involves the analysis of internal and external environments, the current position of the organization is clarified (its mission and objectives), as well as the competitive environment (opportunities and threats) and available resources (strengths and weaknesses). In strategy formulation are the generation and evaluation of the strategic options and the choice of options that will form the organization's strategy. The strategic implementation is the implementation and deployment of strategies in operations, together with the completion of the necessary changes to meet the new strategy, 
which may involve adjustments in the structure and organizational culture (Phaal et al., 2004; 2007).

This is one of the examples that follow the proposal of the T-Plan, proposed by Phaal et al. (2004), but it differs from the standard process. According to Oliveira et al. (2012), it is recommended the adoption of the standard format in the first attempts of application of roadmapping. After some time, the experience gained with the use of this approach will allow adjustments to be made, as those made in this work. Thus, most companies use the T-Plan model as initial form.

The potentiality of the TRM method of stimulating communication between technology and business functions of the organization, integrating TPM triad depends on the planning of activities and goals. In order to assist the start of the use of the method,
Phaal et al. (2004) developed a Fast Start procedure called T-Plan. The T-Plan process was created as a deployment pattern, with the aid of various enterprises that had deployed TRM, and the results obtained by its creators in related searches.

According to Phaal et al. (2004), the main purposes of the T-Plan are to: assist the beginning of the implementation process in the specific context of the company, establish key links between the technological and business drivers, and identify important gaps in the market, product and technology, developing a first version of the technology roadmap.

The T-plan pattern, shown in Figure 5, comprises four facilitation workshops, the first three focusing on the three layers of the roadmap (market/business, products/services and technology). At the end, the three layers are put together, according to the horizon

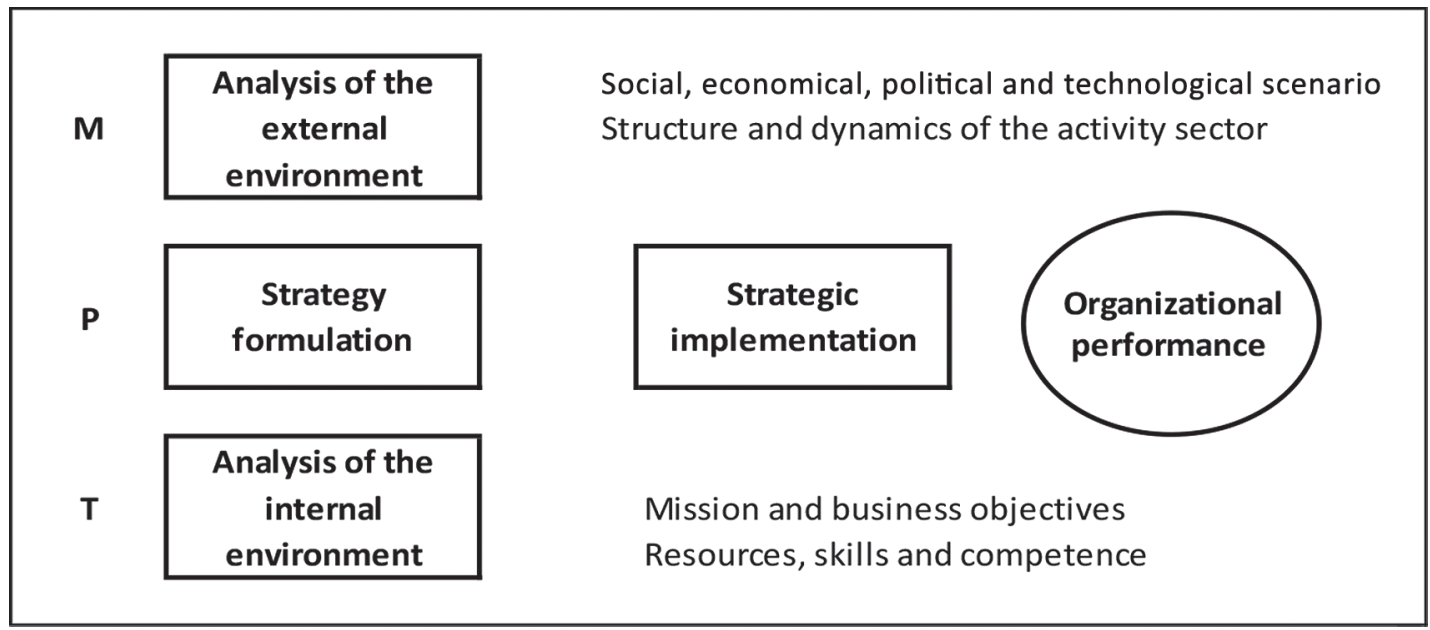

Figure 4. Fundamentals activities of strategic planning. Source: Adapted from Johnson et al. (2008).

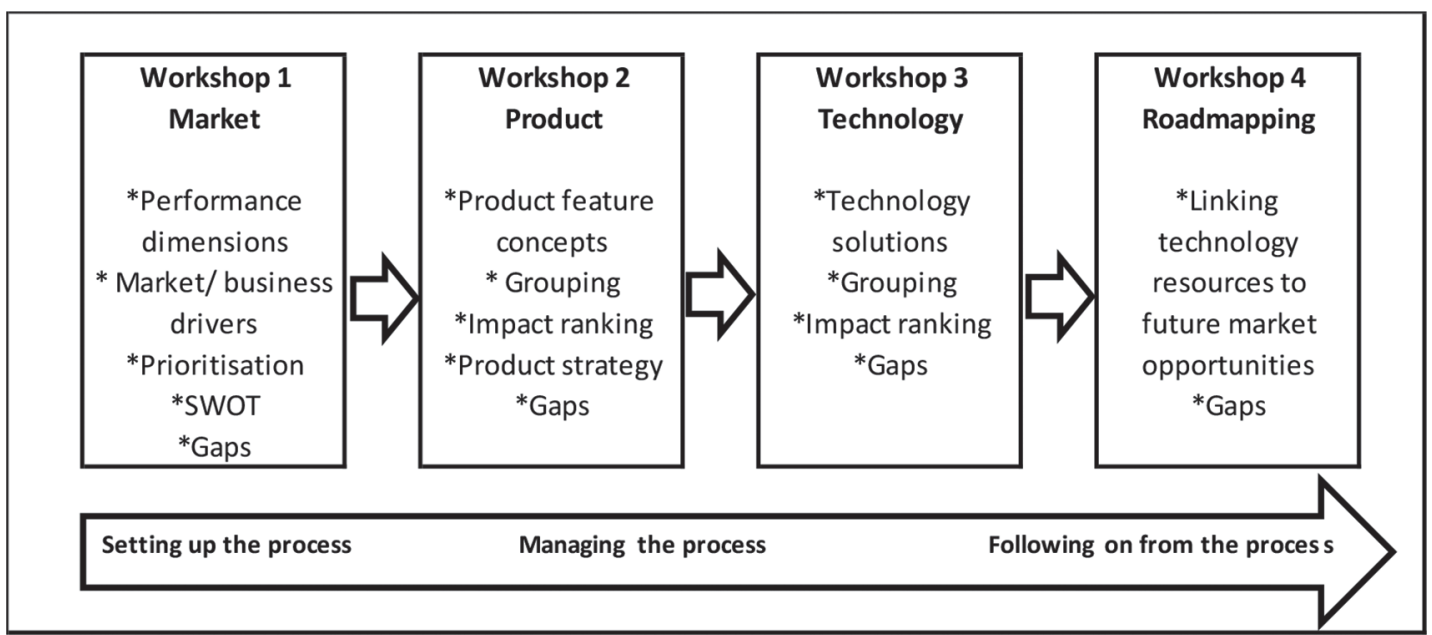

Figure 5. T-Plan fast-start - Standard Process Steps. Source: Phaal et al. (2004). 
to define the roadmap that is prepared after the identification and understanding of the relationships between the different levels and sublevels.

The T-Plan process is a standard process of implantation. However, each TRM application is probably different from another, since the application depends on the specific needs of the organization. The standard method therefore can be modified in various ways so that these needs are met. For example, you can modify the content and level of analysis as well as the format of the map and the planning horizon.

From the foregoing, there is a need to plan the deployment of TRM in the selected organization, as one of its main features is the flexibility. This requires knowledge of the various tools available, their potential and potential limitations, which will be mentioned in due course. The main objective of this work is to open the "black box" of the development of technology roadmaps, namely deepening workshops, addressing what should be done in each one of them and how to do such things that may result in a roadmap able to demonstrate the planning to TBC. In the fourth topic, this paper will discuss the application process and especially the details of this process for TBC, which is the main contribution of this research.

\section{Presentation and analysis of results}

This action research consists of four cycles for the development of the technology roadmap of the company studied. The seminars took three months to build. They were held every two weeks, totaling six seminars. The study was based on the model T-Plan Fast-Start; however, the research aimed to add more specific details to facilitate the preparation of roadmaps, since the model above is generic. The cycles of research were the workshops of market, product, technology and construction of the roadmap itself.

\subsection{First cycle}

Before starting the first cycle, there was a first activity: the planning stage. This activity was important because it allowed the definition of the employees who would participate in the workshops. The members of the company who would participate were five employees in the areas of management, financial, engineering and product development. These employees work in the company since its opening, that is, they know the business very well. The researchers conducted the workshops every fortnight.

At this stage all, the participants were aware of the objectives of the research, which was essentially the development of the company's technology roadmap intended to facilitate its use for TBCs. The company also aimed to acquire a means to better understand its own business and thus be able to properly position its product in the market and track its progress. Having set its goals to the survey, the company had to choose and describe what product or area should be mapped. It chose its main product, which is an automated clinic Chair/Table. This chair intended to help health professionals, especially nurses and technicians to treat burn victims, scarring and chronic wounds. It is important to inform that this product had not been launched yet during the development of this research.

The first cycle was workshop - Market. As mentioned earlier, it has four main parts, which present aspects of product performance: market drivers (internal and external), market segmentation and analysis of strengths/weaknesses and opportunities/threats of the business. Tables 1, 2 and 3 show the meaning and outcome of what was discussed in the first workshop for Hospital Automation Company. This information and the figures illustrate the development of a real roadmap, not a fictional example, so it serves as a step by step of what should be explored.

\subsubsection{Product's performance dimension}

The intent of this first part was to describe aspects of operation and product performance. For this, it was necessary to answer the following guide questions: (1) what are the most important aspects for customers. (2) What customers expect more of its product? Those are terms of technically and measurement of product. The company needed to reflect and put itself in the position of the consumer and know in detail the product. Table 1 presents de attributes of product that were numbered. During the discussions on the dimensions of the product, marketing research could be conducted. This was a

Table 1. Dimensions of product performance.

\begin{tabular}{cc}
\hline Product Attributes & Description \\
\hline Economy & $\begin{array}{r}\text { the product helping reduce costs } \\
\text { (employees, energy) }\end{array}$ \\
Ease of use & $\begin{array}{c}\text { little training is necessary, also features with } \\
\text { easy installation }\end{array}$ \\
Technical assistance & $\begin{array}{c}\text { technical support from company for defects } \\
\text { and other needs } \\
\text { Facility for cleaning } \\
\text { Modularity }\end{array}$ \\
Reliability & $\begin{array}{c}\text { easy maintenance and cleaning } \\
\text { con sold in parts, to meet what the } \\
\text { customer needs } \\
\text { repeatability }\end{array}$ \\
\hline
\end{tabular}

Source: Authors. 
suggestion that occurred at the end of the survey, but it may be valid for future research.

\subsubsection{Market segmentation}

Then it was discussed the major market segments that the product (chair automated for treatment) had. A segment of the market refers to each group of consumers with needs, benefits and/or similar shopping priorities that are determined in the segmentation process in order to filter product and the priorities of the focus of a more consistent (Albright \& Kappel, 2003).

From this new knowledge, the company must choose which segment it wanted to act more strongly so that it could reach more potential customers. In the case, it was chosen the industrial sector segmented by situational factors. Then the company chose the segments it intends to work initially: plastic surgery and scars, burns and wounds. The reasons for the entrepreneur to choose these segments were due to growth in demand for this type of product that meets the health professionals, the relevance that such products need to value creation in this sector and the growing trend of targeting treatments physicians. Thus, during the research it was observed that the analysis of attractiveness of the selected segment is a good practice that also can be incorporated into the model T-Plan.

\subsubsection{Market drivers}

The drivers of the market should be identified and it interprets the voice of the customer. This is the hidden desires and unknown unspoken by the customer, new facets of use and application aspects of product customization (Albright \& Kappel, 2003).

For external market drivers, the company should reflect on what guides effectively the purchase of the product, what are the benefits that customers expect to get through it. Therefore, with the help of a brainstorming followed by discussions and analysis, the drivers were defined. It is noteworthy that there was enough trouble to list the drivers, since many times the concept of driver was complex and confounding. The company initially made an analysis of the benefits that customers expected from the product. At the same time, it should articulate the competitive advantage that these benefits had over competitors Thus, it was necessary to clarify more than once what was considered market driver and how the company should work within those concepts.

From the point that the company understood the concept, it could list several drivers that should be prioritized according to their importance to the business. This analysis of priorities was made by technique of peer review according to Cooper et al. (2001). According to this technique, the company should list several drivers and then prioritize them, in other words, it should choose which was more important (always between two drivers) until the set number of six, for example. The information generated is illustrated in Table 2. As in the case of product performance dimensions, it is appropriate that the company did a market research to confirm or strengthen their knowledge about their drivers.

The choice of these external drivers shows what is fundamental to the company. It is clear that its market mainly search for safety, since it is a health product. Then, it is fundamental for safety to comply with legislation standards. The other drivers are related and pointing to the need for business innovation and technology. The sale of customized way or modularized is essential. The market most expects these aspects from the company's product.

The internal drivers relate to the perspective of the company in relation to its short, medium and long term planning. In this case, the company must identify also through brainstorming, discussions, and reflections and analyzes what impact the product has to the company's strategy. What result does it hope to achieve with this product? What is the company's vision regarding this product?

Table 3 presents the company's internal drivers that were also prioritized according to the technique of peer review. An important aspect of this stage of the workshop is that it generated more demand for the company's actual results, i.e., the product does not present at the time the return that the company wants.

Table 2. Drivers of external market.

\begin{tabular}{|c|c|c|}
\hline Note & External Drivers & Description \\
\hline 10 & Safety & the product must be safe, because it works with the health of people \\
\hline 6.67 & Legislation & must be certified by regulatory bodies \\
\hline 6.67 & Modularity & it should have options to be sold in parts defined by customers \\
\hline 6.67 & Innovative products & an innovative product is a demand from users and patients \\
\hline 5.83 & Technological products & people want to work and be treated with technological products \\
\hline 5.53 & Sales excellence & the company has to know how to sell this type of product and delight customers \\
\hline
\end{tabular}

Source: Authors. 
Table 3. Internal Drivers.

\begin{tabular}{|c|c|c|}
\hline Note & Internal Drivers & Description \\
\hline 10 & Broad company growth & $\begin{array}{l}\text { The manager believes that the company's growth should reach staff, employees and the } \\
\text { community. }\end{array}$ \\
\hline 10 & Align partners (suppliers and logistics) & To develop more and better suppliers and increase its logistics capacity. \\
\hline 7.78 & Increase revenue & It will directly influence job security, wage increases and motivation of employees. \\
\hline 7.78 & $\begin{array}{l}\text { Keep the focus on technology and } \\
\text { innovation }\end{array}$ & $\begin{array}{l}\text { It is a great desire of the company since it emerged from an academic environment and } \\
\text { focusing on innovative R \& D. }\end{array}$ \\
\hline 7.78 & Improve the layout of the company & It will allow increase productivity. \\
\hline 7.78 & Improve people's management & It will enable increase employee training and administration, as well as retaining them. \\
\hline
\end{tabular}

This is because the company is a startup (still in search of a scalable model). It was important for the company to identify driving a process of adjustment/fitting procedure, i.e., it needs to work the product so that it will bring the results you crave it and still not part of your current reality. As exemplified in Table 3, the results for the development of innovation are only perceived in the drivers 1 and 6 . The other demands are adjustments only. As a result, the company should consider adjusting the issues of awareness present in its context.

The choice of these internal market drivers revealed that the product analyzed is the hope of development that the company has. This is clear because of the desire to grow, improve sales and increase business partnerships. To achieve this, the company knows it needs to improve personnel management, improve production layout and remain focused on technology and innovation that are the biggest differences that it has. This internal view was highly praised by the company.

\subsubsection{SWOT analysis}

Finally, the last activity performed was SWOT analysis, presented in Table 4. The SWOT analysis method was chosen because it is a tool used to scenario analysis (or environment analysis), being used as a basis for management and strategic planning of a corporation or company. It is simple and can be used for any type of scenario analysis. SWOT Analysis is a very simple system to position or verify the strategic position of the company in the environment in question. As this study has aimed to simplify the TBCs planning, this method was of great help to understand the company.

The method SWOT is an abbreviation of four focus of analysis, considering the successes achieved goals, strengths, benefits, satisfaction (Force); deficiencies, difficulties, failures, weak aspects, discontent (Weaknesses); potential untapped capabilities, ideas for improvement (Opportunities) and obstacles, adverse context, opposition, resistance to change (Threats) (Dyson, 2004). The SWOT analysis proposed originally by Andrews (1971) is the combination of
Table 4. SWOT analysis.

\begin{tabular}{|c|c|}
\hline Strengths & Opportunities \\
\hline Innovation & promising market (growing) \\
\hline $\begin{array}{l}\text { Time to market high (for } \\
\text { product development) }\end{array}$ & growth specialist clinics \\
\hline Modularity & $\begin{array}{c}\text { many fairs in the sector that } \\
\text { generates good contacts }\end{array}$ \\
\hline Differentiated technology & $\begin{array}{l}\text { indirect competition for the } \\
\text { product }\end{array}$ \\
\hline $\begin{array}{l}\text { Good relationship with the } \\
\text { public }\end{array}$ & $\begin{array}{c}\text { advantage of being a pioneer in } \\
\text { the region }\end{array}$ \\
\hline Weaknesses & Threats \\
\hline Little brand recognition & ease of copying \\
\hline Low working capital & $\begin{array}{c}\text { difficulty obtaining certification } \\
\text { to work }\end{array}$ \\
\hline $\begin{array}{l}\text { Physical structure (production } \\
\text { plant) }\end{array}$ & $\begin{array}{l}\text { large companies in the medical } \\
\text { sector in the country }\end{array}$ \\
\hline Little management knowledge & $\begin{array}{l}\text { low entry barriers in the medical } \\
\text { market }\end{array}$ \\
\hline $\begin{array}{l}\text { Controlling company sectors } \\
\text { (most departments) }\end{array}$ & $\begin{array}{l}\text { regulations for the healthcare } \\
\text { industry is very demanding }\end{array}$ \\
\hline
\end{tabular}

the analysis of the external environment and internal analysis of the company. Despite its recognized importance, companies often do not perform this analysis because of its simplicity. As for the method, as usually happens during SWOT analysis, there was a brainstorming discussion to analyze the information that was being generated.

The company reported that it had made a SWOT analysis when developing the business plan required for joining in business incubator in which it resides. However, due to ignorance on the subject and the inexperience in management, this analysis was unsatisfactory at the time. Therefore, in this new opportunity the company reported to have been much more satisfied with the analysis, since in this new opportunity it could actually understand the benefits that a well-done analysis can bring.

\subsection{Second cycle}

The second cycle was the workshop - Product. The researcher team guided the company members to reflect on the features and product concepts that 
are aligned with market drivers defined in the first workshop. Then the characteristics identified should be evaluated for their contribution to each driver, allowing them to be sorted according to their capabilities. To assess the impact that product attributes exerted on market drivers, the company was advised to follow the following ratings: (0) No relationship, (1) Small relationship, (3) Average relationship and (9) High relationship. Table 5 shows the worksheet that was completed during the research. This spreadsheet model is proposed by T-Plan method. It was filled dynamically; it simply asked what was the relationship between attribute 1 in the driver 1 and so on until its successful completion.

Having made the analysis of the relationship between product attributes and market drivers, the tool was applied to split priorities based on the concept of quality function deployment (QFD). The QFD technique was chosen because it allows a large amount of information to be gathered, in a concise way, in a small number of documents (QFD diagrams). Its chart format is very effective to simplify complex sets of information, as in the case of this research. The applicability of QFD in the development of products and processes is almost unlimited (Cheng \& Melo, 2007).

The QFD technique was applied to calculate the grades that the product attributes and market drivers obtained after analyzing the relationship between them. Regarding grades segment priorities at the top of the spreadsheet, these originate from workshop 1 in which the analysis was performed by pairs of market drivers and their respective prioritization. Finally, the normalized score of the impact that drivers have on the product attributes was calculated.
This standardization is important so that the grades are due on the same scale of grades rating.

The evaluation results showed that the product attributes (economy, reliability, technical assistance and modularity respectively) have greater influence on market drivers. This result was not a surprise to the company, because according to the opinion of its manager, the economic factor is the most important and what initially motivates health workers to invest in new equipment. It was concluded that the economy would come primarily with the reduction of labor to treat patients.

Other characteristics such as reliability, technical assistance and modularity are related to sale of the product, i.e., features that also affect the economics of purchase. As the product is for use in healthcare and uses electrical current it is critical for it to possess reliability, which, in the opinion of the manager, it is related to repeatability in safety to the user and patient. Technical assistance and after sales aspects are basic requirements for customers as well. Finally, the modularity is another basic requirement, because customers want to buy the automated chair according to their needs of use. Thus, the company realized that the product should be offering modularized so it will be a differentiator for its product against future competitors, since it will be seen as a customization.

\subsection{Third cycle}

The third cycle was the workshop - Technology, whose aim was to analyze the technology solutions that enable the company to achieve the characteristics of products identified in the second workshop. According

Table 5. Product X Market Drivers.

\begin{tabular}{|c|c|c|c|c|c|c|c|c|c|c|c|c|c|c|}
\hline \multirow{2}{*}{$\begin{array}{l}\text { Market Segments } \\
\text { Plastic Surgery; Scars, } \\
\text { burns and wounds }\end{array}$} & \multicolumn{12}{|c|}{ Priorities } & & \\
\hline & 10 & 6.7 & 6.7 & 6.7 & 5.8 & 5.8 & 10 & 10 & 7.8 & 7.8 & 7.8 & 7.8 & & \\
\hline & \multicolumn{6}{|c|}{ External Drivers } & \multicolumn{6}{|c|}{ Internal Drivers } & & \\
\hline Product Attributes & $\frac{\vec{E}}{\mathbb{N}^{\pi}}$ & 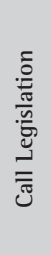 & 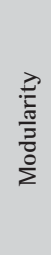 & 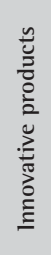 & 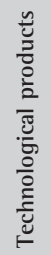 & 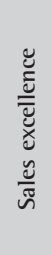 & 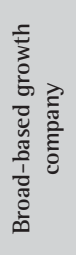 & 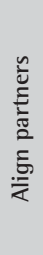 & 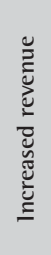 & 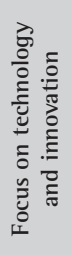 & 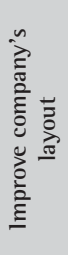 & 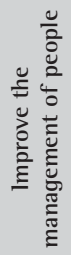 & 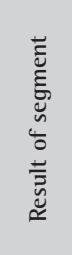 & 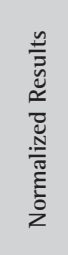 \\
\hline Modularity & 9 & 3 & 9 & 9 & 9 & 1 & 3 & 3 & 9 & 9 & 0 & 0 & 488.4 & 0.454 \\
\hline Ease of use & 1 & 9 & 1 & 3 & 9 & 9 & 0 & 0 & 9 & 9 & 0 & 0 & 341.7 & 0 \\
\hline Reliability & 9 & 9 & 0 & 9 & 9 & 9 & 0 & 9 & 9 & 0 & 3 & 9 & 568.4 & 0.701 \\
\hline Facility for cleaning & 9 & 0 & 9 & 0 & 9 & 9 & 0 & 9 & 0 & 9 & 0 & 9 & 485.0 & 0.443 \\
\hline Technical assistance & 0 & 9 & 9 & 3 & 9 & 9 & 9 & 9 & 9 & 9 & 0 & 0 & 565.1 & 0.691 \\
\hline Economy & 9 & 9 & 0 & 3 & 9 & 9 & 9 & 9 & 9 & 9 & 0 & 9 & 665.0 & 1.000 \\
\hline
\end{tabular}

Source: Authors. 
to Floyd \& Wolf (2010), technology strategy guide the company in the acquisition, development and application of technology in order to obtain competitive advantage, which means to determine which are the main relevant technologies to be developed for the future company and also to develop skills to create and produce from it.

Table 6 shows the form with the identification of the main technologies involved in developing the product studied. All dimensions of product performance were used as reference for identifying technologies. The T-Plan model specifies that in this workshop should be discussed matters related to technology issues, challenges to overcome, existence of facilities and / or difficulties in production (components, materials used, etc..), what hardware and software are needed and skills, knowledge and financial resources. A good practice that was identified during the research

Table 6. Key technologies.

\begin{tabular}{cc}
\hline Technology & Description \\
\hline $\begin{array}{c}\text { Management of R \& D (Filter } \\
\text { of ideas) }\end{array}$ & $\begin{array}{c}\text { Means of relating the product } \\
\text { and the customer } \\
\text { electronics } \\
\text { Enables the choice of the } \\
\text { product benefits to the user } \\
\text { Methods of product } \\
\text { PIC Microcontrollers Embedded } \\
\text { software }\end{array}$ \\
$\begin{array}{c}\text { manufacturing (developed by } \\
\text { the company) } \\
\text { (Germany and China) } \\
\text { Industrial Automation (Electrical } \\
\text { Engineer) }\end{array}$ & $\begin{array}{c}\text { Essential competence for the } \\
\text { company }\end{array}$ \\
$\begin{array}{c}\text { Mechanical design and drawings } \\
\text { (Mechanical Planner) }\end{array}$ & $\begin{array}{c}\text { Develop projects (3D prototypes, } \\
\text { testing) studies of materials } \\
\text { Safety equipment (controls } \\
\text { the electrical current for the } \\
\text { product) required by law }\end{array}$ \\
\hline Source: Authors. &
\end{tabular}

Table 7. Product X Technology.

\begin{tabular}{|c|c|c|c|c|c|c|c|c|}
\hline \multirow{2}{*}{$\begin{array}{c}\text { Market Segments } \\
\text { Plastic surgery; Scars, burns and wounds }\end{array}$} & \multicolumn{6}{|c|}{ Impact of product attribute } & & \\
\hline & 7.35 & 5.14 & 8.55 & 7.29 & 8.50 & 10.00 & & \\
\hline & \multicolumn{6}{|c|}{ PRODUCT ATTRIBUTES } & \multirow[b]{2}{*}{ 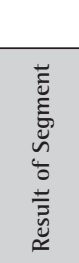 } & \multirow[b]{2}{*}{ 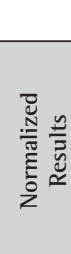 } \\
\hline TECHNOLOGIES & 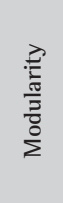 & $\begin{array}{l}\tilde{n} \\
\tilde{z} \\
\overleftarrow{0} \\
\tilde{n} \\
\tilde{w}\end{array}$ & 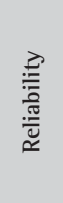 & 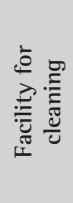 & 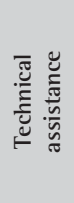 & 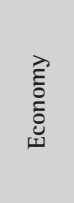 & & \\
\hline Management of R \& D & 3 & 9 & 9 & 9 & 9 & 9 & 377.4 & 1.000 \\
\hline Core R \& D in electronics internal & 3 & 0 & 0 & 0 & 3 & 9 & 137.6 & 0 \\
\hline Source toroidal & 9 & 0 & 0 & 0 & 3 & 9 & 181.7 & 0.184 \\
\hline Industrial Automation (Electrical Engineer) & 9 & 0 & 3 & 0 & 9 & 9 & 258.3 & 0.504 \\
\hline PIC Microcontrollers Embedded software & 9 & 0 & 0 & 0 & 3 & 9 & 181.7 & 0.184 \\
\hline Linear Actuators - Engines (Germany and China) & 9 & 9 & 9 & 3 & 3 & 9 & 326.7 & 0.789 \\
\hline Mechanical design and drawings (Mechanical Planner) & 9 & 3 & 0 & 9 & 9 & 9 & 313.7 & 0.734 \\
\hline
\end{tabular}

and that can be used in future researches would be to seek more partners in the hospital or automation area to be studied, to be held panels using the Delphi research method in order to raise more industrial trends. This suggestion is valid because working only with one company may not be sufficient to identify all technologies and industry trends.

Once the technologies were known, the next task was to complete the worksheet that assessed the impact of technologies on the product attributes identified previously. This analysis can be seen in Table 7. This spreadsheet model is also originating from T-Plan method. It was followed the same classification of workshop product: (0) No relationship, (1) Small relationship, (3) Average relationship and (9) High relationship.

Along with these values, the research team inserted the values of the impact of product attributes on top of the worksheet, which comes from the final result of the previous activity. Finally, it also calculated the normalized score of the impact of technologies on product attributes.

From these results it was possible to note that the technology (R \& D management, linear actuators motors, mechanical design and industrial automation respectively) have greater impact on product attributes. This final grade takes into account the grade received by product attributes, and therefore it can be said that these technologies are responsible for delivering to the product attributes its most important features.

In general, the company works with development of technological products for healthcare. Thus, the issue of managing $R$ \& D is essential to ensure that its products is technologically updated and it still can provide solutions to the market at some point that it is or might be required. Despite the 
management activity being considered a medium, in this case it is essential for the technological research and development. An example is the case of the automated chair study itself, which originated from a demand observed by the company given its constant observation and market research. Thus, the company sought to empower themselves to meet this detected demand. Therefore, it is essential for the company to have surveillance regarding the administration of its ideas and projects. In addition, the company needs to be careful with those employed to be able to retain key employees such as the need for good mechanical designers to develop specific projects. A skilled workforce is a key intangible asset for the company and therefore should be treated as a key part of its technology.

In what concerns the control modules and linear actuators - used motors, the company is aware of its component requirements for production and aims to always acquire them with the best quality and lowest price. It is a constant production challenge.

In the case of this workshop, there was almost no difficulty seeing what the essential technologies were for the company, since most employees work with the technical part of the product and they are used to treat these characteristics as described in the preparation of the research team. Furthermore, this activity aroused the interest of creating a position responsible for activity monitoring technology, which accompanies the technological innovations and facilitates the prediction of future opportunities.

\subsection{Fourth cycle}

Finally, there was the fourth cycle of the action research that was the Roadmapping workshop. At this point, technologies are linked to resources to present opportunities and future markets. There all the definitions of the first three workshops were assembled, leading the technology roadmap. Figure 6 shows a flowchart for the TBCs to use as a facilitator guide to the beginning of the roadmaps of development. Because it is visual, it can help beginners who do not know where to start.

With three layers of the prepared map, participants defined integration and alignment between layers. The first map was shaped like a frame that should be filled with the desired planning for the product. In this initial map, the market drivers were positioned in the upper layer of the map and beneath them the attributes of products, in a way that shows the development of the product that will be released. Finally, the third

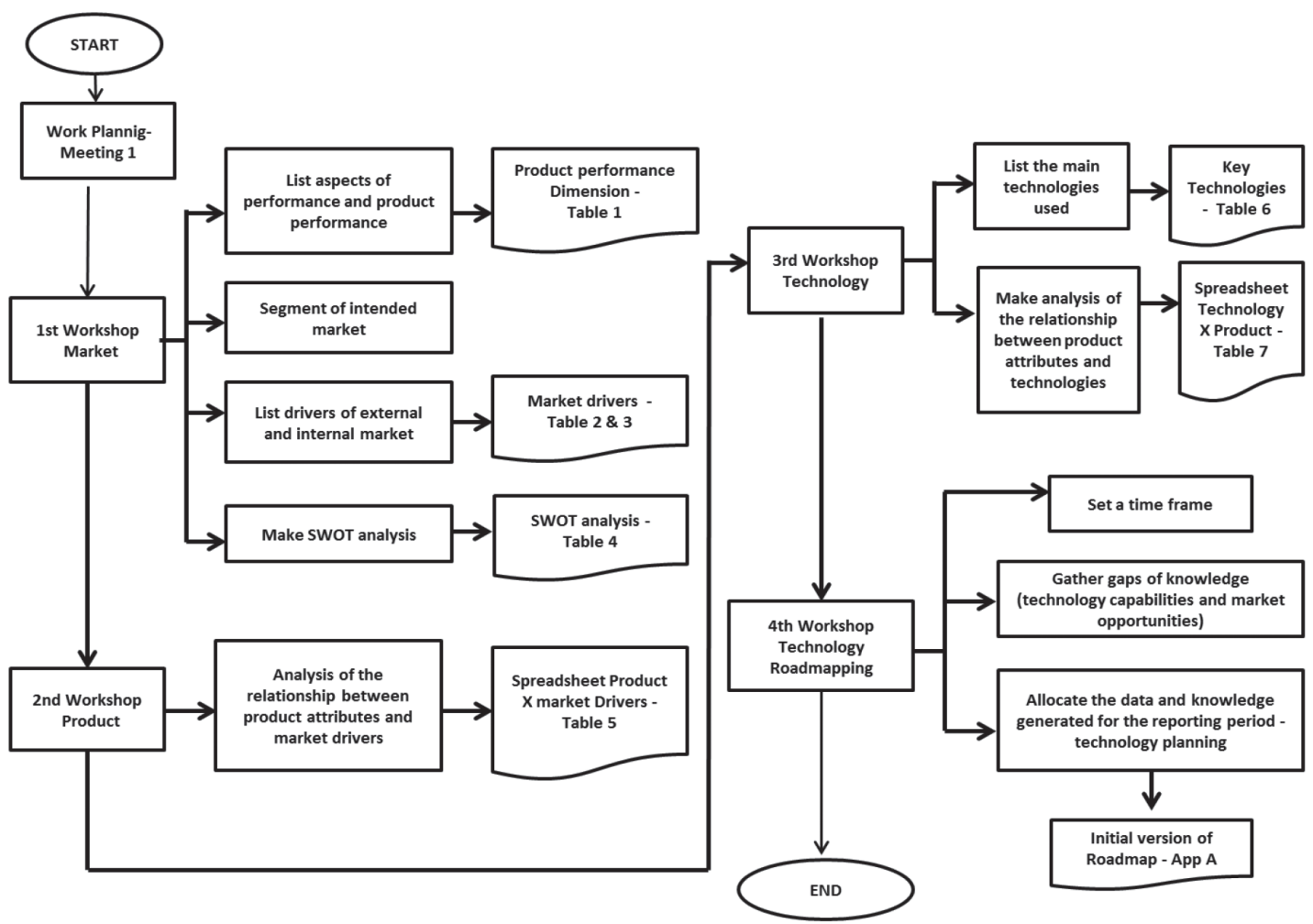

Figure 6. TBC's Flowchart for TRM development. Source: Authors. 
layer was added the necessary technologies that will reach product attributes.

With three layers prepared, the participants defined the first time horizon that should be addressed. This horizon was four semesters. After this, the integration and alignment between layers given the time horizon was done. The final Roadmap developed for the company is shown in Appendix 1A. It is expected that during the four semesters planned, the company make map updates and get ready to develop other maps in the future.

\section{Conclusion}

The technological entrepreneurship that involves the generation of ideas and launching businesses based in technology has been touted as future trends for some decades (Ndonzuau et al., 2002). Despite the successful international experiences, in Brazil, it can be perceived a lack of knowledge about the most effective ways to subsidize, support and promote technological entrepreneurship. The process of product development in technology-based companies is a topic that should be well addressed in the literature, mainly because they are an important agent for the development of local and regional economy.

Thus, this research believes that integration of the triad technology-product-market (TPM) throughout the process of technology planning is essential for the technology management and it can be a rich source of information for product development and business, including not only market issues, but also organizational issues, strategic and financial.

From the company perspective, it is necessary to make selected technology management, and this study sought subsidies in literature and practical analysis of field studies to form a structured procedure based on TRM, in order to facilitate the process of management of technology-based companies and at the same time contribute to the enrichment of academic knowledge.

The methodology used for mapping technology can assist in targeting and technology planning for the short, medium and long term. The main contributions of this work result both of the customization that has been done to develop the roadmap as the association of TRM to technology management. A qualitative and specific advantage provided by this research concerns the decoding of a model (TRM), which was already established in the literature, but for the general public, or potential users of the method, was a black box. With this case developed, TBC can better understand the roadmaps to develop and benefit from the theory that has been published and developed. What, indeed, is one of the T-Plan objectives.

Much has been said about the importance and relevance of the method; however, there is a gap in this research (even more in Brazilian context) that often leaves no doubt about this. It is important to encourage such research, and they must be open in order to show what is or could be involved in each of the dimensions of the triad and the TPM process of roadmapping.

Regarding the contributions of action research, they are more easily perceived in the realm of practice, because their results cannot be generalized. However, the contribution in theory can be constructed from the results obtained in other similar studies. This research, in this sense, reinforces the potential application of TRM in clarifying relevant aspects of the technology planning of TBCs reinforcing the work done previously.

Instead of a few general rules, this work enabled the lifting of various clues, which may be confirmed or refuted in future studies. Future studies are still needed for the systematic proposal to be evolved.

\section{Acknowledgements}

The authors would like to acknowledge the support received from Brazilian funding agencies CAPES, CNPq (Universal Edict 14/2012, Process No. 478509/2012-0) and FAPEMIG.

\section{References}

Albright, R. E., \& Kappel, T. (2003). A roadmapping in the corporation. Research Technology Management, 46(2), 31-40.

Andrade Junior, P. P. (2014). Model for the evaluation of difficulties of technology-based companies in incubators. Production, 24(4), 804-819.

Andrews, K. (1971). The concept of corporate strategy. Homewood, lL: R.D. Irwin.

Brasil. Ministério da Ciência, Tecnologia e Inovação. (2013). Technology parks indicators. Retrieved in 18 October 2013, from http://www.mct.gov.br

Caetano, M., \& Amaral, D. C. (2011). Roadmapping for technology push and partnership: a contribution for open innovation environments. Technovation, 31(3), 320-335. http://dx.doi. org/10.1016/j.technovation.2011.01.005.

Cheng, L. C., \& Melo, L. D. R. (2007). QFD - Quality Function Deployment in product development management. São Paulo: Blücher. 539 p.

Cooper, R. G., Edgett, S. J., \& Kleinschimmidt, E. J. (2001). Portfolio management for new products (2nd ed.). New York: Basic Books.

Coughlan, P., \& Coghlan, D. (2002). Action research for operations management. International Journal of Operations \& Production Management, 22(2), 220-240. http://dx.doi. org/10.1108/01443570210417515. 
Dyson, R. S. (2004). Strategic development and SWOT analysis at the University of Warwick. European Journal of Operational Research, 152(3), 631-640. http://dx.doi.org/10.1016/ S0377-2217(03)00062-6.

Floyd, S. W., \& Wolf, C. (2010). Technology strategy. In V. K. Narayanan \& G. C. O'Connor (Eds.), Encyclopedia of technology and innovation management (pp. 125-128). West Sussex: Wiley.

Gasse, Y. (2002). Entrepreneurship Centres: roles and positioning in the entrepreneurial process. In T. V. Menzies (Ed.), Entrepreneurship and the Canadian universities - strategies and best practices of entrepreneurship centres (pp. 30-35). St. Catharines: Brock University.

Johnson, G., Scholes, K., \& Whittington, R. (2008). Exploring corporate strategy: text and cases (5th ed.). Essex: Prentice Hall Finantial Times.

Lee, S., \& Park, Y. (2005). Customization of technology roadmaps according to roadmapping purposes: overall process and detailed modules. Technological Forecasting and Social Change, 72(5), 567-583. http://dx.doi.org/10.1016/j. techfore.2004.11.006.

Ndonzuau, F. N., Pirnay, F., \& Surlemont, B. (2002). A stage model of academic spinoff creation. Technovation, 22(5), 281-289. http://dx.doi.org/10.1016/S0166-4972(01)00019-0.

Oliveira, M. G., Freitas, J. S., Fleury, A. L., Rozenfeld, H., Phaal, R., Probert, D., \& Cheng, L. C. (2012). Roadmapping: a strategic approach to the management of innovation in products, services and technologies. Rio de Janeiro: Elsevier.

Oliveira, M., \& Rozenfeld, H. (2010). Integrating technology roadmapping and portfolio management at the front-end of new product development. Technological Forecasting and Social Change, 77(8), 1339-1354. http://dx.doi. org/10.1016/j.techfore.2010.07.015.
Phaal, R., Farrukh, C. J. P., \& Probert, D. R. (2004). Technology roadmapping: a planning framework for evolution and revolution. Technological Forecasting and Social Change, 71(1-2), 5-26. http://dx.doi.org/10.1016/S00401625(03)00072-6.

Phaal, R., Farrukh, C. J. P., \& Probert, D. R. (2007). Strategic roadmapping: a workshop-based approach for identifying and exploring strategic issues and opportunities. Engineering Management Journal, 19(1), 3-12. http://dx.doi.org/10.1 080/10429247.2007.11431716.

Porter, M. E. (2008). The five competitive forces that shape strategy. Harvard Business Review, 86(1), 78-94, 137. PMid:18271320.

Rinne, M. (2004). Technological roadmaps: infrastructure for innovation. Technological Forecasting and Social Change, 71(1-2), 67-80. http://dx.doi.org/10.1016/j. techfore.2003.10.002.

Rogers, E. M., Takegami, S., \& Yin, J. (2001). Lesson learned about technology transfer. Technovation, 21(4), 253-261. http://dx.doi.org/10.1016/S0166-4972(00)00039-0.

Shane, S. (2004). Academic entrepreneurship: university spinoffs and wealth creation. Aldershot: Edward Elgar.

Thiollent, M. (2011). Metodologia da pesquisa-ação (18th ed.). São Paulo: Cortez.

Tierney, R., Hermina, W., \& Walsh, S. (2013). The pharmaceutical technology landscape: a new form of technology roadmapping. Technological Forecasting and Social Change, 80(2), 194211. http://dx.doi.org/10.1016/j.techfore.2012.05.002.

Vohora, A., Wright, M., \& Lockett, A. (2004). Critical junctures in the development of university high-tech spinout companies. Research Policy, 33(1), 147-175. http://dx.doi.org/10.1016/ S0048-7333(03)00107-0. 
Appendix 1A. Final version of the roadmap.

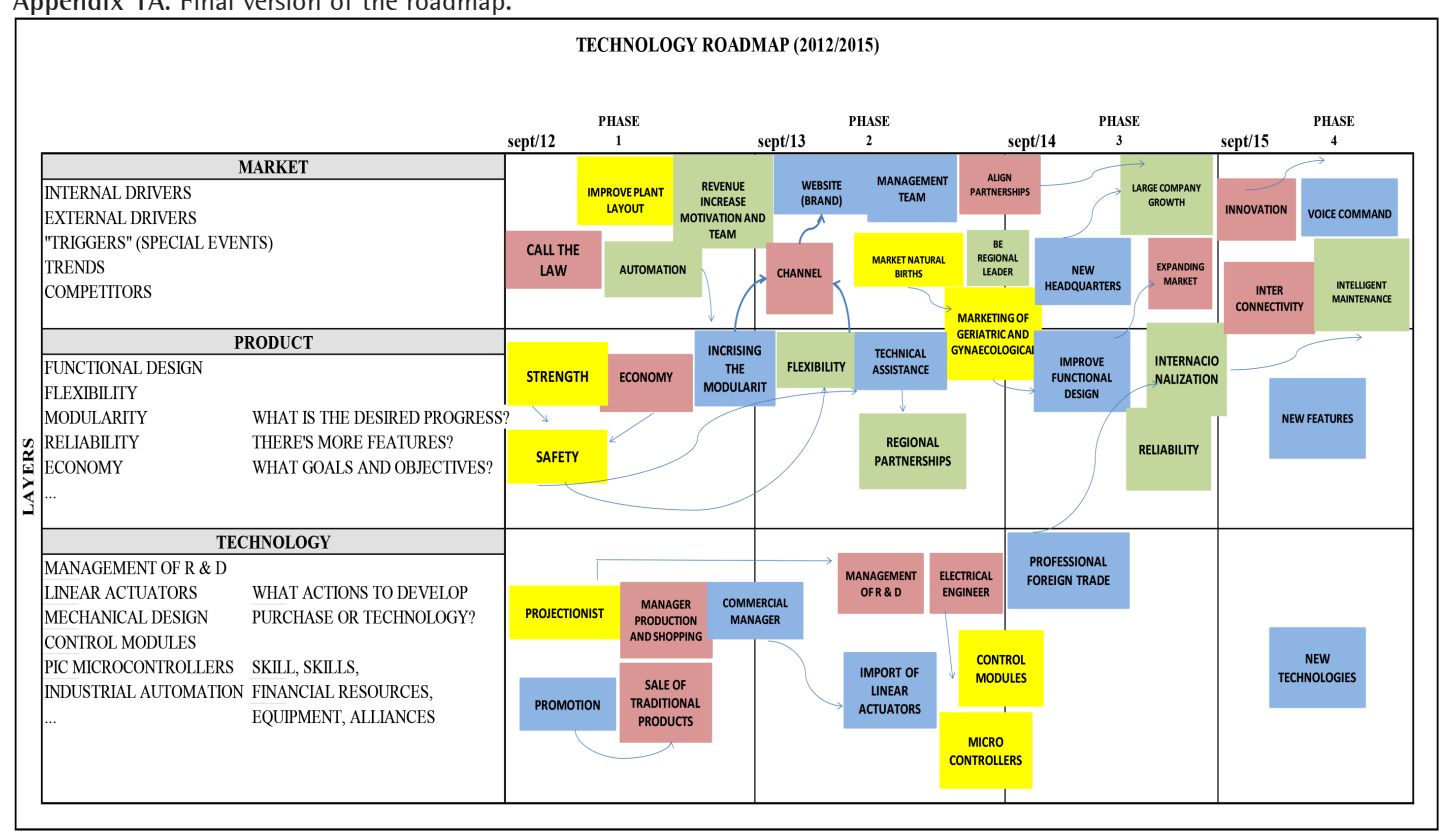

